Journal of Contemporary Educational Research

Research Article

\title{
A Brief Analysis of the Application of Situational Teaching Method in Primary School Music Class
}

Yuchen Zhang

Minzu University of China, Beijing 100080, China

\begin{abstract}
Music situational teaching method aims to mobilize the students' thoughts in a natural state so as to enhance the attractiveness and efficiency of music classes. In the process of this method, some specific situational are designed according to the characteristics of music and under the guidance of psychology, methodology, pedagogy and other theories, and various sensory organs are employed. Different from traditional teaching method, situational teaching method creates learning situational for students, which is consistent with the characteristics of primary school students' physical and mental development and maximizes students' experience and feeling of music.

Key words: Music situational teaching method; Primary school music education; Music class
\end{abstract}

Publication date: October, 2020

Publication online: 31 October, 2020

*Corresponding author: Yuchen Zhang, 3151075550@ qq.com

\section{Introduction}

With the increasingly rich teaching content of music class, the system of teaching method has gradually expanded. Corresponding teaching method should be adopted to match with the cognitive development of students at different age stages and in different teaching sections. The application of pedagogy in primary school music classes is conducive to cultivating students' interest in music and stimulating their potential motivation for learning. Based on the characteristics of music, situational pedagogy restores the essence of music, thus stimulating students' imaginative thinking and creative thinking.

\section{Music situational}

Music refers to a kind of art that harmoniously blends different human voices or instrument sounds which are melodic and rhythm-ed. situational consists of emotion and situationally. Music and situational belong to the category of auditory art and visual art. However, the fact is that both music art and visual art can nourish human soul just like chicken soup can nourish human body, and that they are inseparable because human perception system itself is an inseparable texture ${ }^{[1]}$.

As a matter of fact, painters are often inspired by music, and musicians often use visual elements as subjects to express music. So it can be said that music and paint influence and interpenetrate mutually.

\subsection{The emotive function of music}

According to Records of Music, music expresses emotion through sound and emotion comes from people's real life reflection. "Where sound begins, the human heart begins. When the heart moves, things move. We feel things moving, shaped by sound." The music is born in sound and originally lies in people feeling things. "According to Records of Music, the changes of external things bring about various changes in people's feelings, which is expressed by music. There are similar expressions in The Preface of Mao's poems: "Emotion comes from sound, the sound is written to music. Music in prosperous times is peaceful and joyful because of political leniency; music in turbulent times is resentful and angry because of politics. The music of the dead country, sad and sentimental, covers the exile of its people from the great depression. "So people can find emotional clues in music. 


\subsection{The ideographic function of music}

Based on the ability to perform synesthetic responses in abstract sound effects, people are able to associate not only images but also the colors expressed by music. Take the textbook of People's Music Press version for Grade Five to Spring as the example. The piece of music is the most famous piece among Edward Grieg's 66 lyrical piano sketches. The music adopts The music adopts trilogy, rising $\mathrm{F}$ major, allegro and $6 / 4$ beat. A major triad composed of the main chord is played continuously in the treble area at the beginning of the piece, as if the spring is approaching slowly. The long low voice added under the background, just like a smooth Lyric solo, which is simple and warm, full of praise for spring. We can feel the green and vitality of spring at the beginning of the music. When bars 28-36 appear, the whole range of the music moves down and the music turns tense to make people hold their breath and look forward to the new things coming. Bar 4547 shows that the theme melody is so soft and relaxed against the background of decompose and chords, it seems that people can feel the blooming of spring flowers all over the mountains and fields, and also present colorful spring scenery.

China's music curriculum standards emphasize the "aesthetic" of music. The so-called ability to feel, express, appreciate and create beauty is the ability to visualize music, which requires students to feel the potential artistic conception from the abstract music melody $^{[2]}$. From this point of view, expression and ideogram are the essential properties of music. The application of pedagogy in primary school music classes is conducive to cultivating students' interest in music and stimulating their potential motivation for learning ${ }^{[3]}$. Based on the characteristics of music, situational pedagogy restores the essence of music, thus stimulating students' imaginative thinking and creative thinking.

\section{Situational Teaching method}

Under the guidance of psychology, methodology, pedagogy and other theories, the music situational teaching method uses the participation of various senses to design some specific scenes according to the characteristics of music, so that students can actively mobilize their thinking in the natural state and enhance the attraction of music class to achieve the purpose of high efficiency. Different from the traditional teaching method, situational teaching method creates a learning situation for students, which is consistent with the physical and mental development characteristics of primary school students. This teaching method maximizes the students' experience and feelings of $\operatorname{music}^{[4]}$.

\subsection{Basic types of situational teaching method}

\subsubsection{Verbal scenario}

Verbal situational mainly describes the abstract music melody through vivid language and words, so as to help students establish the picture sense. This is the most convenient type, which is not limited by equipment materials and space, and can be carried out anytime, anywhere. Psychological research found that students' learning is accidental, and music learning is closely related to life, music is everywhere. Therefore, teachers can flexibly use speech art to assist the music scene, which can achieve twice the result with half the effort.

\subsubsection{Picture situational}

Picture situational has two presentation modes: static picture and dynamic video, which requires the participation of teaching equipment and teaching aids, and is relatively simple in operation. According to the basic law of students' cognitive development, visual perception is one of the main forms of intuitive teaching ${ }^{[5]}$. Teachers can help students quickly establish visual images through intuitive pictures or prepared video materials, especially the things with low relevance to students' living environment or ages far apart.

\subsubsection{Participative scenario}

Participatory scenarios mainly include game scenarios and deductive scenarios. The former requires students to actively participate in music situational games, focusing on classroom interaction; the latter requires students to master the basic emotions of music and understand the basic connotation of music, and then make secondary creation ${ }^{[6]}$. Through the coordination of scene arrangement, stage performance and music scheduling to present the complete music works. This is the most complex type of operation, and it is also the most active one to cultivate students' music comprehensive quality. Take "the magician's disciple" as an example: This is a musical Symphony poem, which was created by French composer Descartes in $1897^{[7]}$. The main theme of the presentation part I (Bar 72-77). The little disciples of the three big pipes playing 
the magician arbitrarily cast a spell on the broom and let it carry water automatically. The theme of the music is the step sound of the broom led by the little disciple. After jumping into the pure fifth degree and upgrading to the lower octave scale, the music continues to repeat in the form of small three small jumps, followed by the descending of the scale, and then changes and repeats. In the meantime, there is a short tune in $\mathrm{C}$ minor at the climax of the melody. The range of theme one is only developed in an octave, which fully depicts the humorous and lively music image of the broom which is enchanted by the younger disciples when they walk ${ }^{[8]}$.

There are both contrast and connection between the theme materials. The work revolves around these kinds of materials and their various forms. The materials are highly unified and concise. As a classic soundtrack of Disney animation, this piece of work has rich story plot, which can be played by students in the course of editing and creating. Through facial expression, body language and other aspects of joint participation and performance, students change a variety of musical emotions. This kind of participatory interaction can cultivate students' ability to explore independently. In the process of cooperation, students can learn to position the role, figure out the psychological characteristics of the role, and show the effect of music learning in the classroom through externalized actions.

\subsection{The role of situational teaching method}

\subsubsection{Develop interest in music}

The goal of music course is to establish the concept of students' lifelong learning of music, and cultivating interest is the driving force of students' continuous learning ${ }^{[9]}$. rom the perspective of cognitive psychology, situational teaching method fits the cognitive structure and thinking level of primary school students. The situational teaching method can not only improve students' sense of participation but also eliminate their fear of difficulty in music learning by making abstract music images concrete. It is found that when children acquire high self-esteem in a certain field, their time of continuous exploration will increase significantly. Therefore, situational teaching method plays a significant role in promoting the cultivation of students' interest in music.

\subsubsection{Enrich emotional experience}

With the development of society, living conditions are getting better and better, but our living environment has also undergone great changes. With the gradual distance between man and nature, the surge of pressure leads to various social problems gradually exposed, among which children's psychological diseases are becoming more and more common. Long term solitude and closed learning make children lack of direct experience, which leads to the lack of sensory ability ${ }^{[10]}$.

The experience of music scene can make up for this deficiency to a certain extent. Through the interaction in music class to promote positive emotional experience. For example, "Rhapsody in the forest" in textbook of People's Music Press version. This piece of music works is very special. Apart from melody performance, a large number of natural real sounds are used. This is a form of music that emerged in the 1970s and was first used to help meditate and cleanse the mind. It is not only a category, but a category different from the past ${ }^{[11]}$. From the works, we can directly feel the sound of water and birds, which makes people calm and relaxed. Among them, the sound of waves, running water, birds singing and wind blowing through the leaves, and also the sound of rain hitting on the roof give people a feeling of returning to nature.Obviously, the use of situational teaching method in this appreciation work, on the one hand, can enrich the natural experience of primary school students, on the other hand, it can relieve the pressure on their studies ${ }^{[12]}$.

\subsubsection{Stimulate creative thinking}

In all kinds of music situations, the first is the percep$\operatorname{tion}^{[13]}$. On the basis of fully perceiving the music scene, the students use the comprehension ability to construct the vivid speech scene, expand the rich association according to the picture scene, and flexibly use the memory reserve of music knowledge and skills to perform the relevant music scene deduction. In the whole process of situational teaching, perception and thinking are throughout ${ }^{[14]}$. Therefore, in the process of music situational teaching, only when students' cognitive abilities are balanced can they provide favorable preconditions for the stimulation of creativity. From the cognitive point of view, primary school students' creative thinking is in an active period, music classroom teaching should seize this critical period to stimulate students' creative potential.

\section{Conclusion}

In a word, situational teaching method is widely used in music class, its purpose is to assist music teaching, 
improve the efficiency of the classroom, and cultivate students' interest in music. Any effective method has its own limitations, and abuse beyond the scope will only backfire. Excessive scenario setting will make students form fixed thinking and seriously limit the development of students' imagination. We should adhere to the original intention of music education, and appropriately use situational teaching method as a favorable means to promote music education.

\section{References}

[1] Yong DQ. Music Teaching Method [M]. Southwest Normal University Press, 2016: 93-106.

[2] Lu L. Practice and Research of Junior Middle School Music Teaching based on the concept of "Student-based"[J]. Contemporary music, 2016(24): 40.

[3] Mo KY, Reform and Innovation of Primary School Music Education Teaching Methods and Ideas[J]. Guide to Knowledge, 2017(28): 20.

[4] Ge RH. Importance of Situational Music Teaching in primary School[J]. Grand View, 2015(2): 12.

[5] Xiong CH. Importance and Application of Situational Teaching
[J]. Children's Music, 2011(7): 50-52.

[6] Zhang HH. Situational Teaching in Music Teaching [J]. Hebei Education, 1997(5): 77.

[7] Zhou J. Doka symphonic Poem "The Magician's Disciple" [J]. Shaanxi Education (Higher Education Edition), 2011(Z2): 2326

[8] Kuang XF, Huang Z. Some Understandings on the development of thematic exposition (melody) [J].Journal of Wuhan Conservatory of Music. 1998(04):63.

[9] [English] Kirk (D. Cooke), Music Language [M]. People's Music Publishing House, 1981: 160-164.

[10] Xia F. Research on music Situational Teaching based on the characteristics of psychological development of primary school students[J]. Navigation in arts and Sciences, Educational Research and Practice, 2018(10): 54-58.

[11] Wang L. On the cultivation of elementary school students' music teaching atmosphere[J]. Scientific Chinese,2015(4Z): 36.

[12] Xu N. Discussion on music Therapy to Relieve College Students' Psychological Pressure [J]. Contemporary Educational Practice and Teaching Research, 2018(5): 991.

[13] Chen Y. On the Teaching method of Music[J]. Examination Papers and Research (Teaching Forum), 2018(18): 28.

[14] He JR. Discussion on Situational Music Teaching in primary School[J]. Reading \& Writing, 2018(1): 17-20. 